\title{
Synthesis of Polythioamide from Dithiocarboxylic acid-O,O-diethyl esters and Diamines by Room-Temperature Polycondensation
}

\author{
Kohei Sanui, Yasushi Kishimoto, and Naoya Ogata \\ Department of Chemistry, Sophia University, \\ Kioi-cho, Chiyoda-ku, Tokyo, Japan.
}

(Received May 19, 1971)

\begin{abstract}
Various dithiocarboxylic acid-O,O-diethyl esters were synthesized and the polycondensation reaction with diamines was investigated. The polycondensation reaction of dithiocarboxylic acid-O,O-diethyl esters with hexamethylenediamine(HD) took place at room temperature to form polythioamide in solution in a good yield. The rate of the polycondersation reaction of aromatic dithiocarboxylic acid-O,O-diethyl esters with HD was greatly influenced by solvents, which retarded the rate in the following decreasing order: DMSO $>$ DMF $>$ DMAc $>$ NMP $>$ THF $>$ EtOH $>$ EtOH $-\mathrm{H}_{2} \mathrm{O}(50 / 50)$. It was also found that solvents had a strong influence on the structure or the molecular weight of obtained polythioamide and particularly such solvents as DMF, DMAc or DMSO were effective for the formation of a linear and a high-molecular-weight polythioamide, while in ethanol an insoluble polymer with a cross-linked structure was obtained. However, aliphatic O,O-dithioester tended to form an insoluble polymer even in such solvents as DMF, DMAc or DMSO, compared with aromatic O,O-dithioester.

KEY WORDS Room-temperature Polycondensation / Diamine / Dithiocarboxylic Acid Ester / Polythioamide /
\end{abstract}

Polycondensation reaction is usually carried out in melt method by heating monomers above the melting point of the final polymer and the reaction is accompanied by equilibrium which is continually displaced to the polymer formation by removal of the more volatile products such as water or alcohol from the reaction system. Therefore, the rate of polycondensation is apparently influenced by the elimination rate of these volatile products from the reaction vessel.

However, when an active substituent is introduced in a monomer structure, the reactivity of functional groups such as amino or carbonyl increases to such a great extent that the polycondensation reaction is apparently not influenced by equilibrium. Thus, for instance, polyamide can be prepared at a relatively low temperature by the interfacial or low-temperature solution polycondensation which is based on the Schotten -Baumann reaction where acid chloride is used in place of carboxylic acid.

Recently, it was found that exchange reaction is an effective method to prepare condensation polymers at low temperature. For instance, the following exchange reactions are known to be effective to prepare aliphatic or aromatic polyamides with a high molecular weight at a low temperature:

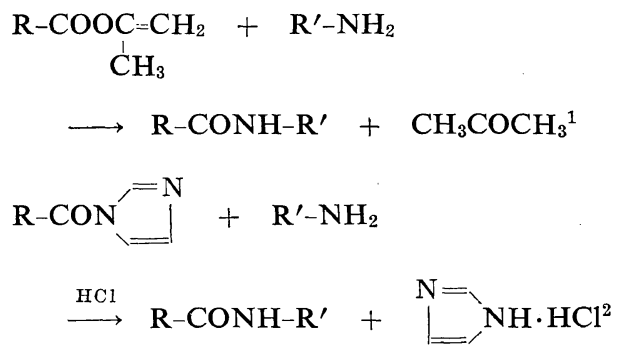

It is found ${ }^{3}$ that the polycondensation reaction of amine and carboxylic acid ester proceeded at room temperature even in alcohol solution when a hydroxyethyl group was introduced on the nitrogen atom of amine, and a hydrophilic polyamide having pendant hydroxyethyl groups was obtained by the room-temperature polycondensation of $N$-(hydroxyethyl)- $\beta$-alanine ester $^{4}$ or $N, N^{\prime}$-(dihydroxyethyl)diamine and dicarboxylic acid ester ${ }^{5}$ in an alcoholic solution. Also, carboxylic acid ester having a thioether 
group at the $\beta$-position to the carbonyl group reacted with amine at room temperature to form an amide compound even in alcohol, and this reaction could be applied to yield polyamide in a mild reaction condition. This peculiar behavior of carboxylic acid ester having the $\beta$-thioether group led us to study the condensation reaction of thiocarboxylic acid ester with amine.

Thiocarboxylic acid-O-ester ${ }^{6}$ is known to react easily with ammonia at low temperature to form a thioamide compound.

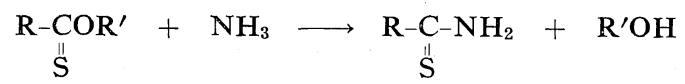

It was reported in a previous paper ${ }^{7}$ that this reaction could be extended to the polycondensation reaction of dithiocarboxylic acid-O,Odiesters with diamines to form polythioamide at a relatively low temperature.

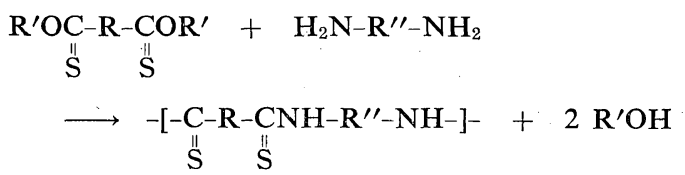

In this study, the polycondensation of various dithiocarboxylic acid-O,O-diethyl esters with diamines was carried out in the presence of a basic catalyst such as lithium ethoxide. Polycondensation conditions have been investigated in connection with temperature, monomer concentration, metal complex, and solvent effects. Also, a model reaction between thiopropionic acid-O-ethyl ester with n-butylamine, n-butyl alcohol or $n$-butyl mercaptan was carried out in order to elucidate the role of the thiocarbonyl group on the polycondensation.

\section{EXPERIMENTAL}

\section{Material}

Commercially available hexamethylenediamine and ethylenediamine of the reagent first grade were distilled twice under reduced pressure before use. Commercial 4,4'-diaminodiphenyl ether was purified by recrystallization from ethanol. Solvents such as benzene, ethanol, THF, DMF, DMAc, DMSO, NMP, and HMPA were purified by the usual procedures. Commercially available metal acetylacetonates were purified by recrystallization.

\section{Synthesis of Monomers}

Dithiocarboxylic acid-O,O-diethyl esters were synthesized by routes as shown below:

$$
\begin{aligned}
& \text { NC-R-CN }+2 \mathrm{C}_{2} \mathrm{H}_{5} \mathrm{OH} \\
& \underset{\text { in benzene }}{\stackrel{\text { dry-HC1 }}{\longrightarrow}} \quad \stackrel{\mathrm{ClH} \cdot \mathrm{HN}_{2}}{\mathrm{C}_{2} \mathrm{H}_{5} \mathrm{O}} \stackrel{\mathrm{C}-\mathrm{R}-\mathrm{C} / \mathrm{OC}_{2} \mathrm{H}_{5}}{\mathrm{NH} \cdot \mathrm{HCl}}
\end{aligned}
$$

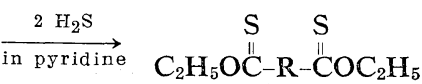

Dicarboxylic Acid Bisiminoethyl Ester Hydrochlorides. A portion of $0.25 \mathrm{~mol}$ of dinitrile and $30 \mathrm{ml}$ of absolute ethanol were dissolved in $400 \mathrm{~m} l$ of dry benzene. The solution was saturated by dry hydrogen chloride gas with cooling for $4 \mathrm{hr}$. The precipitated product was collected, followed by washing with dry benzene and drying in vacuo for more than $12 \mathrm{hr}$. The yield and melting points of dicarboxylic acid bisimino-

\begin{tabular}{|c|c|c|}
\hline $\mathrm{R}$ & Yield, $\%$ & $\mathrm{mp},{ }^{\circ} \mathrm{C}$ \\
\hline$-\left(\mathrm{CH}_{2}\right)_{4}-$ & 90.0 & $154-158$ \\
\hline & 82.1 & $188-190$ \\
\hline & 71.1 & $295-298.5$ \\
\hline
\end{tabular}
ethyl ester hydrochlorides were as follows:

Dithioadipic Acid-O,O-diethyl Ester. A portion of $27.3 \mathrm{~g}$ of adipic acid bisiminoethyl ester hydrochloride and $50 \mathrm{~m} l$ of triethylamine were mixed together in $200 \mathrm{ml}$ of dry pyridine. A dry hydrogen sulfide gas was introduced into the solution for $8 \mathrm{hr}$ and then the solution was poured into cold water containing an excess of hydrochloric acid, followed by extraction with ether. The ether solution was dried over anhydrous sodium sulfate. After the removal of ether, distillation of dithioester was repeated three times for purification: yield, 10\%; bp 125 $-128^{\circ} \mathrm{C}(2 \mathrm{~mm})$.

Anal. Calcd for $\mathrm{C}_{10} \mathrm{H}_{18} \mathrm{O}_{2} \mathrm{~S}_{2}$ : C, 51.27; H, 7.75. Found: C, 51.79; H, 7.72.

Aromatic Dithiocarboxylic Acid-O,O-diethyl esters. A portion of $50 \mathrm{~g}(0.17 \mathrm{~mol})$ of aromatic dicarboxylic acid bisiminoethyl ester hydrochlo- 
ride and $100 \mathrm{ml}$ of triethylamine were mixed together in $300 \mathrm{ml}$ of pyridine. A dry hydrogen sulfide gas was introduced into the solution for $6 \mathrm{hr}$. The product was obtained as a yellow precipitate by pouring the mixture into cold water containing an excess of hydrochloric acid. The precipitate was filtered, followed by washing with water, and then dissolved in benzene. The benzene solution was dried over anhydrous sodium sulfate. After evaporating benzene, the residue was purified by repeated reprecipitation from benzene- $n$-hexane. Physical constants of obtained thioesters were as follows:

\section{RESULTS AND DISCUSSION}

\section{Polycondensation}

The rates of the polycondensation of dithioadipic acid-O,O-diethyl ester(DTAA), dithioisophthalic acid-O,O-diethyl ester(DTIP) or dithioterephthalic acid-O,O-diethyl ester(DTTP) with hexamethylenediamine(HD) were determined in the concentration of $0.25 \mathrm{~mol} / l$ in various solvents at $30^{\circ} \mathrm{C}$ and the results are shown in Figure $1-3$, respectively. The rate of the polycondensation reaction was greatly influenced by solvents, which retarded the rate in the follow-

\begin{tabular}{|c|c|c|c|c|c|c|}
\hline \multirow{3}{*}{ Dithioester } & \multirow{3}{*}{ Yield, $\%$} & \multirow{3}{*}{$\mathrm{mp},{ }^{\circ} \mathrm{C}$} & \multicolumn{4}{|c|}{ Anal. } \\
\hline & & & \multicolumn{2}{|c|}{ C, $\%$} & \multicolumn{2}{|c|}{$\mathrm{H}, \%$} \\
\hline & & & Found & Calcd & Found & Calcd \\
\hline$>$-CSOEt & 61 & $87-88$ & 57.02 & 56.66 & 5.80 & 5.55 \\
\hline EtOCS- & 66 & $62-63$ & 55.71 & 56.66 & 5.57 & 5.55 \\
\hline
\end{tabular}

\section{Solution Polycondensation}

A given amount of dithiocarboxylic acid-O, O-diethyl esters and diamines was dissolved in various solvents in the presence of $5 \mathrm{~mol} \%$ of lithium ethoxide and the solution was kept at a constant temperature. The rate of the polycondensation reaction was determined in a given period either by titration of residual amine in the solution or by gas-chromatographic analysis of yielded alcohol in the solution. After the reaction was completed, the solution was poured into water and the resulting polymers were filtered, followed by washing with water and benzene, and dried.

\section{Measurement}

The characterization of the polymer was done by elementary and infrared analyses, and the molecular weight was determined by an amino end group titration in a 75/25 mixture of THF and water. The solution viscosity of polythioamides was measured in concentrated sulfuric acid at $30^{\circ} \mathrm{C}$. The melting point of the polymers was measured by differential thermal analysis. ing decreasing order: DMSO $>$ DMF $>$ DMAc $>$ $\mathrm{NMP}>\mathrm{THF}>\mathrm{EtOH}>\mathrm{EtOH}-\mathrm{H}_{2} \mathrm{O}(50 / 50)>\mathrm{DM}-$ $\mathrm{Ac}-\mathrm{H}_{2} \mathrm{O}(50 / 50)>\mathrm{DMSO}-\mathrm{H}_{2} \mathrm{O}(50 / 50)$, as shown in Figures 1-3. It is seen in these Figures that the polycondensation reaction of various dithiocarboxylic acid-O,O-diesters with HD in solvents such as DMSO, DMF or DMAc was com-

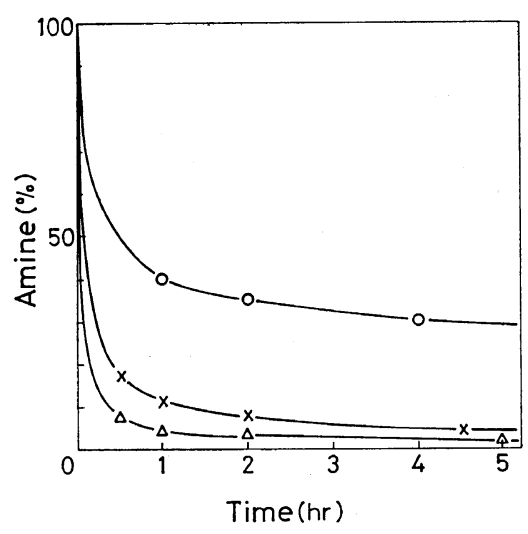

Figure 1. Rates of the polycondensation of DTAA and $\mathrm{HD}$ in various solvents at $30^{\circ} \mathrm{C}$ : monomer concn, $0.25 \mathrm{~mol} / l$; catalyst, EtOli, $5 \mathrm{~mol} \%$; $\bigcirc$, EtOH; $\times$, THF; $\triangle$, DMF. 


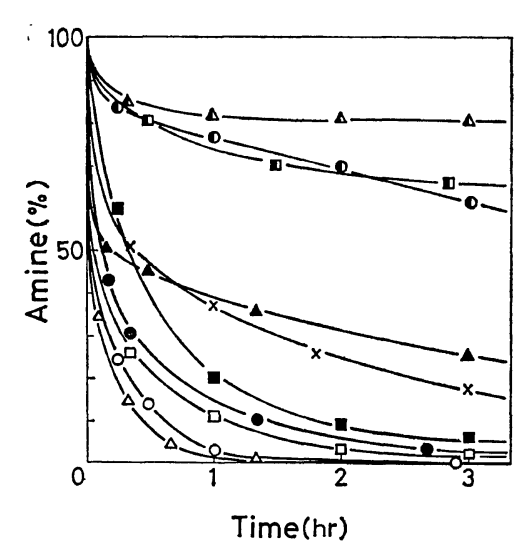

Figure 2. Rates of the polycondensation of DTIP and $\mathrm{HD}$ in various solvents at $30^{\circ} \mathrm{C}$ : monomer concn, $0.25 \mathrm{~mol} / l$; catalyst, EtOLi, $5 \mathrm{~mol} \%$; $\bigcirc$, DMF; $\triangle$, DMSO; $\square$, DMAc;, NMP; $\triangle$, HNPA; $\square$, THF; $\times$, EtOH; $\triangle, \mathrm{DMSO} / \mathrm{H}_{2} \mathrm{O}=50 / 50 ; \square$, DMAc $/ \mathrm{H}_{2} \mathrm{O}=50 / 50 ; \mathrm{D}, \mathrm{EtOH} / \mathrm{H}_{2} \mathrm{O}=50 / 50$.

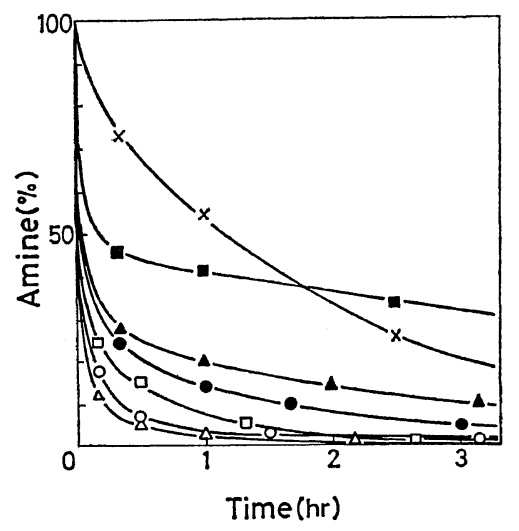

Figure 3. Rates of the polycondensation of DTTP and $\mathrm{HD}$ in various solvents at $30^{\circ} \mathrm{C}$ : monomer concn, $0.20 \mathrm{~mol} / l$; catalyst, EtOLi, $5 \mathrm{~mol} \%$; $\bigcirc$, DMF; $\triangle$, DMSO; $\square$, DMAc; $\bullet$, NMP; $\triangle$, HMPA; 口, THF; $\times$, EtOH.

pleted within a few hours at $30^{\circ} \mathrm{C}$ and the polycondensation reaction took place even in ethanol, which suggested that the reaction was apparently not under the influence of chemical equilibrium since the ethanol was eliminated during this reaction.

The rates of the polycondensation of various dithiocarboxylic acid-O,O-diethyl esters with diamines in DMF in the concentration of 0.25 $\mathrm{mol} / \mathrm{l}$ at $30^{\circ} \mathrm{C}$ are shown in Figure 4 , which in- dicates that the polycondensation reaction of DTIP or DTTP with aromatic diamine is very slow, compared with that of aliphatic diamine. The reactivity of diamine $\left(\mathrm{H}_{2} \mathrm{~N}-\mathrm{R}-\mathrm{NH}_{2}\right)$ with $\mathrm{O}, \mathrm{O}$-dithioester decreased in the following order:

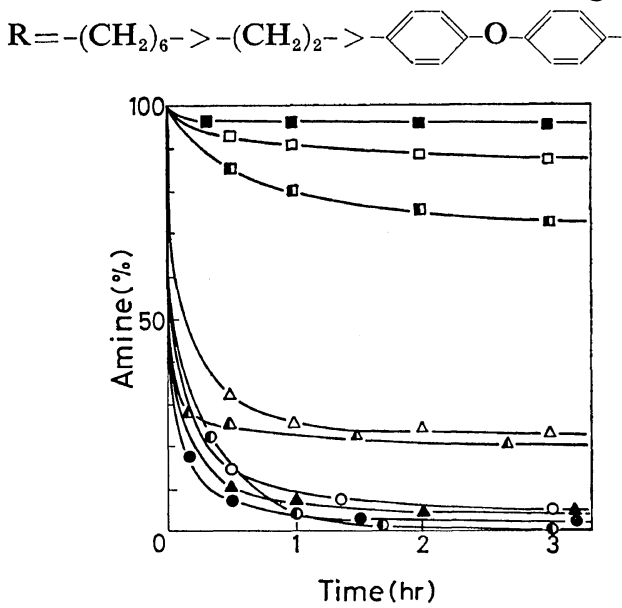

Figure 4. Rates of the polycondensation of EtOC $-\mathrm{R}-\stackrel{\mathrm{COEt}}{\mathrm{C}}$ and $\mathrm{H}_{2} \mathrm{~N}-\mathrm{R}^{\prime}-\mathrm{NH}_{2}$ in $\mathrm{DMF}$ at $30^{\circ} \mathrm{C}$ : monomer concn, $0.25 \mathrm{~mol} / l$; catalyst, EtOLi, 5 mol\%;

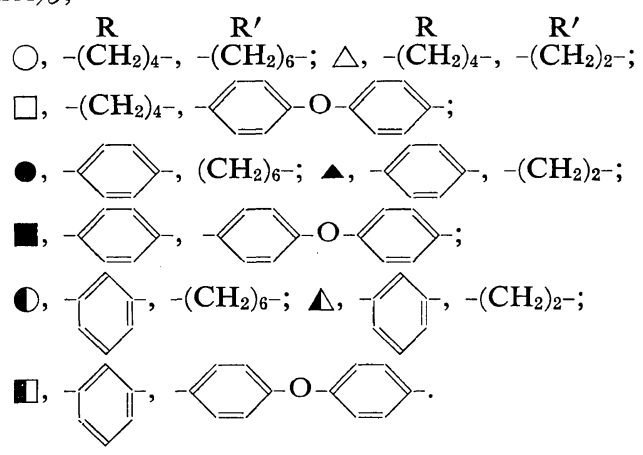

Results of the polycondensation of DTAA or aromatic $\mathrm{O}, \mathrm{O}$-dithioesters with diamines in various solvents are summarized in Table I and II, respectively. It is found in Table I that aliphatic dithiocarboxylic acid ester tends to form an insoluble polymer and the reaction with HD results in the formation of the insoluble polymer even in such low concentrations as $0.1 \mathrm{~mol} / l$ and at $0^{\circ} \mathrm{C}$. On the other hand, Table II shows that solvents have a marked influence on the structure of obtained polymers and an insoluble polymer with a rubber-like elasticity was formed in 
Synthesis of Polythioamide

Table I. Polycondensation of DTAA and diamines ${ }^{a}$

\begin{tabular}{|c|c|c|c|c|c|c|}
\hline \multirow{2}{*}{$\begin{array}{l}\text { Monomer } \\
\text { diamine }\end{array}$} & \multicolumn{3}{|c|}{ Condition } & \multicolumn{3}{|c|}{ Polymer } \\
\hline & Solvent & $\underset{{ }^{\circ} \mathrm{C}}{\text { Temp }}$ & $\begin{array}{c}\text { Time, } \\
\text { day }\end{array}$ & Yield, & $\eta_{\mathrm{sp}} / c^{\mathrm{b}}$ & $\underset{{ }^{\circ} \mathrm{C}}{\mathrm{PMT}^{\mathrm{c}},}$ \\
\hline $\begin{array}{l}\mathrm{H}_{2} \mathrm{~N}-\left(\mathrm{CH}_{2}\right)_{6}-\mathrm{NH}_{2} \\
\mathrm{H}_{2} \mathrm{~N}-\left(\mathrm{CH}_{2}\right)_{6}-\mathrm{NH}_{2} \\
\mathrm{H}_{2} \mathrm{~N}-\left(\mathrm{CH}_{2}\right)_{6}-\mathrm{NH}_{2} \\
\mathrm{H}_{2} \mathrm{~N}-\left(\mathrm{CH}_{2}\right)_{6}-\mathrm{NH}_{2} \\
\mathrm{H}_{2} \mathrm{~N}-\left(\mathrm{CH}_{2}\right)_{6}-\mathrm{NH}_{2} \\
\mathrm{H}_{2} \mathrm{~N}-\left(\mathrm{CH}_{2}\right)_{2}-\mathrm{NH}_{2} \\
\left(\mathrm{HOCH}{ }_{2} \mathrm{CH}_{2} \mathrm{NHCH}_{2-}\right)_{2} \mathrm{NHCH}_{2}\end{array}$ & $\begin{array}{l}\text { EtOH } \\
\text { THF } \\
\text { DMF } \\
\text { DMFd } \\
\text { DMSO } \\
\text { DMF } \\
\text { EtOH }\end{array}$ & $\begin{array}{r}30 \\
30 \\
30 \\
0 \\
30 \\
30 \\
30\end{array}$ & $\begin{array}{r}10 \\
10 \\
10 \\
1 \\
1 \\
2 \\
6\end{array}$ & $\begin{array}{l}100 \\
100 \\
100 \\
100 \\
100 \\
38.0 \\
64.0\end{array}$ & $\begin{array}{l}\text { Insoluble } \\
\text { Insoluble } \\
\text { Insoluble } \\
\text { Insoluble } \\
\text { Insoluble } \\
0.08 \\
0.06\end{array}$ & $\begin{array}{r}(260) \\
(260) \\
(260) \\
(260) \\
(260) \\
136-140 \\
-\end{array}$ \\
\hline $\mathrm{H}_{2} \mathrm{~N}-4$ & DMF & 30 & 48 & 67.3 & 0.09 & $(300)$ \\
\hline
\end{tabular}

a Monomer concn, $0.25 \mathrm{~mol} / l$. b $0.05 \mathrm{~g} / 10 \mathrm{ml}$ in $\mathrm{H}_{2} \mathrm{SO}_{4}$ at $30^{\circ} \mathrm{C}$. c Polymer melting temperature. ( ), decomposition temp. ¿ Momomer concn, $0.10 \mathrm{~mol} / l$. e in vacuo.

$\mathrm{S} S$

Table II. Polycondensation of EtOC-R-COEt and $\mathrm{H}_{2} \mathrm{~N}-\mathrm{R}^{\prime}-\mathrm{NH}$ in various solvents ${ }^{\mathrm{a}}$

\begin{tabular}{|c|c|c|c|c|c|c|c|c|}
\hline \multirow{2}{*}{\multicolumn{2}{|c|}{ Monomer }} & \multicolumn{2}{|c|}{ Condition } & \multicolumn{3}{|c|}{ Polymer } & \multirow{3}{*}{$M_{n}$} & \multirow{3}{*}{$\underset{{ }^{\circ} \mathrm{C}}{\mathrm{PMT},{ }^{\mathrm{c}}}$} \\
\hline & & \multirow[t]{2}{*}{ Solvent } & \multirow{2}{*}{$\underset{\mathrm{hr}}{\text { Time, }}$} & \multirow{2}{*}{\multicolumn{2}{|c|}{$\frac{\text { Yield, } \%}{\text { Soluble Insoluble }}$}} & \multirow{2}{*}{$\eta_{\mathrm{sp}} / c^{\mathrm{b}}$} & & \\
\hline $\mathbf{R}$ & $\mathbf{R}^{\prime}$ & & & & & & & \\
\hline & $-\left(\mathrm{CH}_{2}\right)_{2^{-}}$ & DMF & 22 & 91.0 & 0 & 0.12 & 3200 & $184-220$ \\
\hline " & " & DMSO & 24 & 84.7 & 0 & 0.13 & 3500 & $200-225$ \\
\hline 11 & " & DMAc & 24 & 78.1 & 0 & 0.11 & 3200 & $185-220$ \\
\hline$" 1$ & " & THF & 24 & 49.7 & 33.5 & 0.09 & 2800 & $182-215$ \\
\hline$"$ & " & EtOH & 23 & 81.3 & 0 & 0.10 & 3300 & $185-220$ \\
\hline$" \prime$ & $-\left(\mathrm{CH}_{2}\right)_{6^{-}}$ & DMF & 26 & 96.8 & 2.9 & 0.24 & 5200 & $98-125$ \\
\hline$"$ & "I & DMSO & 26 & 94.2 & 0 & 0.18 & 5200 & $98-125$ \\
\hline$" \prime$ & " & DMAc & 26 & 98.1 & 1.4 & 0.27 & 5800 & $106-132$ \\
\hline$" \prime$ & " & NMP & 26 & 93.5 & 0 & 0.15 & 3600 & $95-125$ \\
\hline$" \prime$ & " & HMPA & 25 & 84.9 & 0 & 0.14 & 3900 & $95-125$ \\
\hline$" \prime$ & $" \prime$ & THF & 26 & 84.6 & 13.9 & 0.17 & 4900 & $81-115$ \\
\hline$" \prime$ & " & EtOH & 24 & 0 & 100 & - & - & $(210)$ \\
\hline " & " & $\underset{(50 / 50)}{\mathrm{EtOH}-\mathrm{H}_{2} \mathrm{O}}$ & 95 & 0 & 32.7 & - & - & $(210)$ \\
\hline " & " & 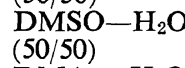 & $\mathrm{O}_{50}$ & 7.4 & 13.7 & - & - & - \\
\hline$"$ & " & $\begin{array}{l}\text { DMAc }-\mathrm{H}_{2} \mathrm{O} \\
(50 / 50)\end{array}$ & $\mathrm{O}_{50}$ & 13.8 & 30.2 & 0.11 & 2800 & $84-118$ \\
\hline$" 1$ & " & $\underset{(95 / 5)}{\mathrm{DMAc}-\mathrm{H}_{2} \mathrm{O}}$ & $\mathrm{O}_{23}$ & 69.0 & 3.5 & 0.12 & 3200 & $98-125$ \\
\hline 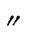 & & $>-D M F$ & $54^{\mathrm{d}}$ & 94.5 & 0 & 0.21 & 4900 & $175-190$ \\
\hline 11 & " & DMSO & $9^{d}$ & 69.6 & 0 & 0.08 & 2700 & $167-185$ \\
\hline & $-\left(\mathrm{CH}_{2}\right)_{2^{-}}$ & DMF & 24 & 90.0 & 0 & 0.09 & - & $190-220$ \\
\hline$"$ & $-\left(\mathrm{CH}_{2}\right)_{6^{-}}$ & DMF & 24 & 75.3 & 0 & $0.22 *$ & 一 & $150-155$ \\
\hline$" 1$ & 11 & DMSO & 24 & 100 & 0 & 0.22 & - & $150-155$ \\
\hline$" 1$ & " & DMAc & 25 & 97.3 & 2.2 & 0.19 & - & $150-155$ \\
\hline "I & " & NMP & 25 & 94.0 & 3.0 & 0.14 & - & $146-155$ \\
\hline$" 1$ & " & HMPA & 25 & 95.5 & 0 & 0.20 & - & $150-155$ \\
\hline$" \prime$ & " & THF & 49 & 64.3 & 28.4 & 0.17 & - & $145-155$ \\
\hline$"$ & " & EtOH & 46 & 0 & 100 & - & - & $(270)$ \\
\hline
\end{tabular}

a Monomer concn, $0.25 \mathrm{~mol} / \mathrm{l}$, at $30^{\circ} \mathrm{C}$; catalyst, EtOLi $=5 \mathrm{~mol} \%$.

b $0.05 \mathrm{~g} / 10 \mathrm{~m} l$ in DMF $\left(* \mathrm{H}_{2} \mathrm{SO}_{4}\right)$ at $30^{\circ} \mathrm{C}$.

c Polymer melting temp; ( ), decomposition temp.

d Day. 
THF and particularly in ethanol during the polycondensation of aromatic $\mathbf{O}, \mathrm{O}$-dithioesters with diamines, while the reaction in solvents such as DMSO, DMF or DMAc proceeded in a homogeneous phase and gave a high-molecular-weight polythioamide which was soluble in these solvents.

Figures 5 and 6 show the effect of temperature and monomer concentration on the polycondensation of DTIP with HD in DMF, respectively, where it is seen that the rates of the polycondensation increase with increasing monomer concentration and with rising temperature.

Effects of monomer concentration on the

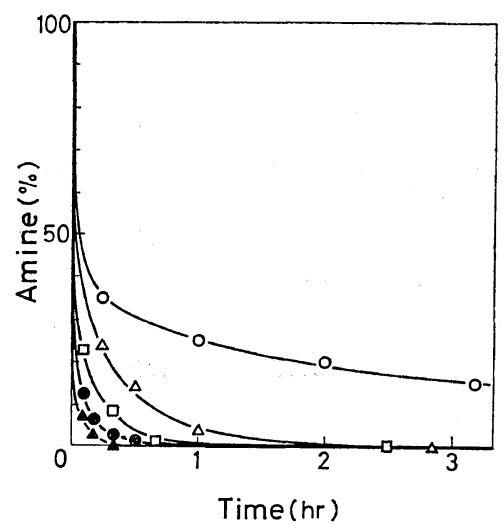

Figure 5. Rates of the polycondensation of DTIP and $\mathrm{HD}$ at various concentrations: solvent, DMF; temp, $30^{\circ} \mathrm{C}$; catalyst, EtOLi, $5 \mathrm{~mol} \%$; $\bigcirc, 0.10 \mathrm{~mol} / \mathrm{l}$; $\triangle, 0.25 \mathrm{~mol} / l ; \square, 0.50 \mathrm{~mol} / l ; 0,0.75 \mathrm{~mol} / l ; \Delta, 1.00$ $\mathrm{mol} / l$ at $60^{\circ} \mathrm{C}$.

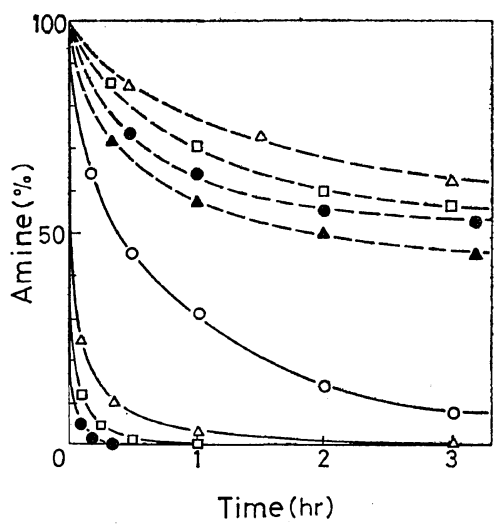

Figure 6. Rates of the polycondensation of DTIP and $\mathrm{H}_{2} \mathrm{~N}-\left(\mathrm{CH}_{2}\right)_{6}-\mathrm{NH}_{2}(-)$ or $\mathrm{H}_{2} \mathrm{~N}-\longrightarrow-$ $\measuredangle-\mathrm{NH}_{2}(--)$ at various temperatures: monomer concn, $0.50 \mathrm{~mol} / l$ in DMF; catalyst, EtOLi, $5 \mathrm{~mol} \%$; $\bigcirc, 0^{\circ} \mathrm{C} ; \triangle, 30^{\circ} \mathrm{C} ; \square, 60^{\circ} \mathrm{C}$; ․․ $100^{\circ} \mathrm{C} ; \Delta$, $153^{\circ} \mathrm{C}$.

polycondensation reaction of DTIP with $H D$ in DMF and DMAc are summarized in Table III. Table III shows that the amount of soluble polymers increases with increasing monomer concentration and both the yield and the molecular weight of soluble polymers are highest in the monomer concentration of $0.5-0.75 \mathrm{~mol} / l$. However, the insoluble polymer was obtained quantitatively when the monomer concentration exceeded $1.0 \mathrm{~mol} / l$.

On the other hand, no effect of temperature

Table III. Effect of monomer concentration on the polycondensation of DTIP and HDa

\begin{tabular}{|c|c|c|c|c|c|}
\hline \multirow{3}{*}{ Solvent } & \multirow{3}{*}{$\begin{array}{c}\text { Condition conen, } \\
\mathrm{mol} / l\end{array}$} & \multirow{3}{*}{$\underset{\mathrm{hr}}{\text { Time }}$} & \multicolumn{3}{|c|}{ Polymer } \\
\hline & & & \multicolumn{2}{|c|}{ Yield, $\%$} & \multirow[t]{2}{*}{$\eta_{\mathrm{sp}} / \mathcal{c}^{\mathrm{b}}$} \\
\hline & & & Soluble & Insoluble & \\
\hline DMAc & 0.10 & 25 & 57.1 & 16.7 & 0.07 \\
\hline DMAc & 0.25 & 26 & 98.1 & 1.4 & 0.27 \\
\hline DMAc & 0.50 & 23 & 98.6 & 0 & $0.30 *$ \\
\hline $\mathrm{DMF}$ & 0.10 & 50 & 21.4 & 12.7 & 0.06 \\
\hline DMF & 0.25 & 26 & 96.8 & 2.9 & 0.24 \\
\hline DMF & 0.50 & 26 & 98.3 & 0 & 0.26 \\
\hline DMF & 0.75 & 25 & 100 & 0 & 0.25 \\
\hline DMF & $1.00^{\mathrm{c}}$ & 10 & 0 & 100 & - \\
\hline
\end{tabular}

a Reaction temp, $30^{\circ} \mathrm{C}$, catalyst, EtOLi, $5 \mathrm{~mol} \%$.

b $0.05 \mathrm{~g} / 10 \mathrm{~m} l$ in $\mathrm{DMF}\left({ }^{*} \mathrm{H}_{2} \mathrm{SO}_{4}\right)$ at $30^{\circ} \mathrm{C}$.

c At $60^{\circ} \mathrm{C}$. 
Synthesis of Polythioamide

Table IV. Effect of temperature on the polycondensation of EtOC-R-COEt and $\mathrm{H}_{2} \mathrm{~N}-\mathrm{R}^{\prime}-\mathrm{NH}_{2}$ in $\mathrm{DMF}^{\mathrm{a}}$

\begin{tabular}{|c|c|c|c|c|c|c|c|}
\hline \multirow{2}{*}{\multicolumn{2}{|c|}{ Monomer }} & \multicolumn{2}{|c|}{ Condition } & \multicolumn{3}{|c|}{ Polymer } & \multirow{3}{*}{$M_{n}$} \\
\hline & & \multirow{2}{*}{${ }^{\circ} \mathrm{C}$} & \multirow{2}{*}{ Time, } & \multicolumn{2}{|c|}{ Yield, $\%$} & \multirow{2}{*}{$\eta_{\mathrm{sp}} / c^{\mathrm{b}}$} & \\
\hline $\mathbf{R}$ & $\mathbf{R}^{\prime}$ & & & Soluble & Insoluble & & \\
\hline & $-\left(\mathrm{CH}_{2}\right)_{6^{-}}$ & 0 & 24 & 90.0 & 4.5 & 0.25 & 5000 \\
\hline$"$ & $" \prime$ & 30 & 26 & 98.3 & 0 & 0.26 & 5500 \\
\hline$" \prime$ & " & 60 & 22 & 99.4 & 0 & 0.32 & 6500 \\
\hline$" 1$ & " & 100 & 5 & 99.8 & 0 & 0.31 & 6500 \\
\hline$" 1$ & $" \prime$ & 153 & 5 & 99.6 & 0 & 0.28 & 6000 \\
\hline " & " & $153^{c}$ & 5 & 0 & 100 & - & - \\
\hline " & & 30 & 310 & 51.5 & 0 & 0.11 & - \\
\hline " & " & 60 & 315 & 67.4 & 0 & 0.11 & - \\
\hline " & " & 100 & 15 & 43.9 & 0 & 0.12 & - \\
\hline " & " & 153 & 30 & 76.0 & 0 & 0.17 & - \\
\hline & $-\left(\mathrm{CH}_{2}\right)_{6^{-}}$ & 0 & 24 & 92.7 & 1.9 & 0.25 & - \\
\hline$=$ & " & 30 & 24 & 99.2 & 0 & 0.27 & - \\
\hline " & " & 60 & 60 & 98.8 & 0 & 0.31 & - \\
\hline$" 1$ & " & 153 & 5 & 98.5 & 0 & 0.31 & - \\
\hline
\end{tabular}

a Monomer concn, $0.50 \mathrm{~mol} / l$; catalyst, EtOLi, $5 \mathrm{~mol} \%$.

b $0.05 \mathrm{~g} / 10 \mathrm{~m} l$ in $\mathrm{DMF}$ at $30^{\circ} \mathrm{C}$.

c None solvent.

on the structure or the molecular weight of resulting polymers was observed in the polycondensation of DTIP or DTTP with HD, as indicated in Table IV. The polythioamide having a molecular weight of about 6500 and an inherent viscosity of more than 0.30 was obtained in the monomer concentration of $0.5 \mathrm{~mol} / l$ at $60^{\circ} \mathrm{C}$. It was also found that the solution polycondensation of DTIP with HD at $0^{\circ} \mathrm{C}$ or the bulk polycondensation at $153^{\circ} \mathrm{C}$ resulted in the formation of an insoluble polymer.

The rates of the polycondensation of DTIP with $\mathrm{HD}$ in the presence of $10 \mathrm{wt} \% /$ monomer of metal acetylacetonates are shown in Figure 7 , where it is seen that the reaction is accelerated by these metal acetylacetonates and the catalytic activity of metal acetylacetonates decreases in the following order:

$\mathrm{Mg}>\mathrm{Ni}, \mathrm{Co}>\mathrm{Fe}, \mathrm{Zn}>\mathrm{Li}, \mathrm{Th}>\mathrm{Cu}, \mathrm{Zr}>$ None.

However, the metal complex did not have a significant influence on the molecular weight of yielded polymers as can be seen in Table V.

Table V. Polycondensation of DTIP and HD in the presence of metal acetyl acetonates ${ }^{\mathrm{a}}$

\begin{tabular}{lcccc}
\hline M(AcAc $)_{x}{ }^{\mathrm{b}}$ & $\begin{array}{c}\text { Time, } \\
\text { hr }\end{array}$ & \multicolumn{2}{c}{ Yield, $\%$} & \multicolumn{2}{c}{ Soluble Insoluble } & $\eta_{\mathrm{sp}} / c^{\mathrm{c}}$ \\
\hline $\mathrm{Li}$ & 24 & 94.3 & 0 & 0.20 \\
$\mathrm{Mg}$ & 24 & 96.0 & 0 & 0.18 \\
$\mathrm{Th}$ & 25 & 100 & 0 & 0.26 \\
$\mathrm{Zr}$ & 26 & 94.4 & 2.4 & 0.18 \\
$\mathrm{Fe}$ & 24 & 89.0 & 8.4 & 0.19 \\
$\mathrm{Co}$ & 24 & 80.7 & 12.9 & 0.18 \\
$\mathrm{Ni}$ & 25 & 83.9 & 10.6 & 0.18 \\
$\mathrm{Cu}$ & 26 & 96.2 & 3.1 & 0.17 \\
$\mathrm{Zu}$ & 25 & 93.0 & 5.8 & 0.16 \\
$\mathrm{None}$ & 23 & 94.2 & 0 & 0.16 \\
\end{tabular}

a Monomer concn, $0.25 \mathrm{~mol} / \mathrm{l}$ in $\mathrm{DMF}$ at $30^{\circ} \mathrm{C}$.

b $\mathrm{M}(\mathrm{AcAc})_{x}=10 \mathrm{wt} \%$.

c $0.05 \mathrm{~g} / 10 \mathrm{ml}$ in DMF at $30^{\circ} \mathrm{C}$. 
The accelerating effect of these metal acetylacetonates may be related to the chelating complex formation at the intermediate stage during the reaction, which may take place between the metal and thiocarbonyl or thioamide groups to enhance the reactivity. However, concrete evidence of the complex formation has not yet been found.

\section{Polymer Structures}

Soluble polymers could dissolve in THF, $m$ cresol, DMF, DMAc or concentrated sulfuric acid and they were insoluble in benzene, chloroform or acetone. Insoluble polymers which were precipitated out of the solution during the polycondensation reaction could not dissolve in any common organic solvents.

Elementary analyses of soluble and insoluble polymers were in close agreement with the expected structure as follows:

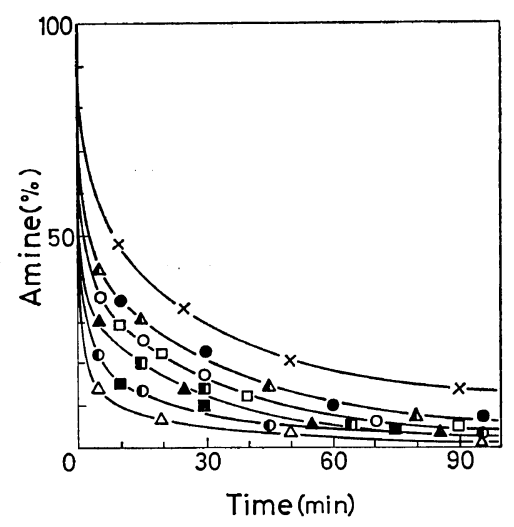

Figure 7. Rates of the polycondensation of DTIP and $H D$ in the presence of $10 \mathrm{wt} \% /$ monomer of metal acetyl acetonates: monomer concn, $0.25 \mathrm{~mol} / l$ in $\mathrm{DMF}$ at $30^{\circ} \mathrm{C} ; \bigcirc, \mathrm{Li}(\mathrm{AcAc}) ; \triangle, \mathrm{Mg}(\mathrm{AcAc})_{2}$; $\square, \operatorname{Th}(\mathrm{AcAc})_{4} ; \bigcirc, \operatorname{Zr}(\mathrm{AcAc})_{4} ; \Delta, \mathrm{Fe}(\mathrm{AcAc})_{3} ; \mathbf{\square}$, $\mathrm{Co}(\mathrm{AcAc})_{2} ; \bigcirc, \mathrm{Ni}(\mathrm{AcAc})_{2} ; \triangle, \mathrm{Cu}(\mathrm{AcAc})_{2} ; \square, \mathrm{Zn}$ $(\mathrm{AcAc})_{2} ; \times$, None.

\begin{tabular}{|c|c|c|c|c|c|c|}
\hline \multirow{3}{*}{ Polymer } & \multicolumn{6}{|c|}{ Anal. } \\
\hline & \multicolumn{3}{|c|}{ Found } & \multicolumn{3}{|c|}{ Calcd } \\
\hline & $\mathrm{C}, \%$ & $\mathrm{H}, \%$ & $\mathrm{~N}, \%$ & C, $\%$ & $\mathrm{H}, \%$ & $\mathrm{~N}, \%$ \\
\hline$-\left[-\mathrm{CS}\left(\mathrm{CH}_{2}\right)_{4} \mathrm{CSNH}\left(\mathrm{CH}_{2}\right)_{6} \mathrm{NH}-\right]-$ & 47.53 & 6.19 & 13.63 & 47.52 & 6.98 & 13.86 \\
\hline$\left.-\mathrm{CSNH}\left(\mathrm{CH}_{2}\right)_{6} \mathrm{NH}-\right]-$ & 59.80 & 6.56 & 9.41 & 60.42 & 6.52 & 10.07 \\
\hline$\left.-\mathrm{CSNH}\left(\mathrm{CH}_{2}\right)_{2} \mathrm{NH}-\right]-$ & 52.64 & 6.04 & 12.06 & 53.05 & 6.25 & 12.38 \\
\hline$\left.-\mathrm{CSNH}\left(\mathrm{CH}_{2}\right)_{6} \mathrm{NH}-\right]_{-}^{-}$ & 60.10 & 6.50 & 9.54 & 60.42 & 6.52 & 10.07 \\
\hline $\mathrm{CS}-$ & 65.11 & 4.43 & 7.03 & 66.27 & 3.90 & 7.73 \\
\hline
\end{tabular}

Infrared spectra of soluble and insoluble polymers are shown in Figure 8. Infrared spectrum of the soluble polymer exhibits typical absorptions owing to the thioamide group, while the infrared spectrum of the insoluble polymer showed weak absorptions at 3200 and $1560 \mathrm{~cm}^{-1}$, which could be assigned to absorption owing to the $\mathrm{N}-\mathrm{H}$ group and thioamide II, respectively. New absorptions appeared at 1660 and $650 \mathrm{~cm}^{-1}$ which could be attributed to absorptions owing to $-\mathrm{C}=\mathrm{N}-$ and $-\mathrm{C}-\mathrm{S}-$ groups, when compared with those of soluble polymers. An insoluble polymer with a crosslinked structure was quantitatively obtained when an oxygen gas was introduced into the DMF solution in the monomer concentration of $0.25 \mathrm{~mol} / l$ at $30^{\circ} \mathrm{C}$. Therefore, a crosslinking reaction might occur among thioamide groups of polymer chains to form the insoluble polymer as follows:

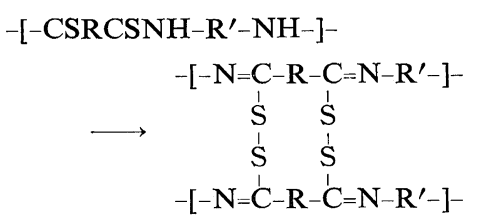

Polymer J., Vol. 2, No. 6, 1971 


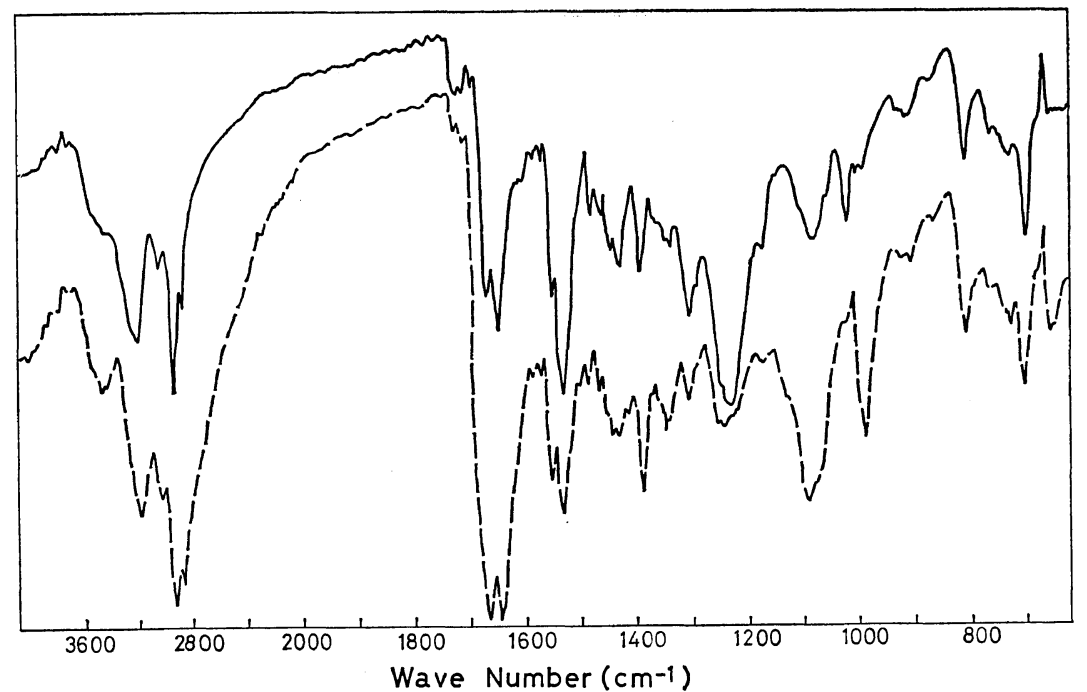

Figure 8. Infrared spectra of polymer from DTIP and $\mathrm{HD}(\mathrm{KBr})$ : - soluble polymer; ---, insoluble polymer.

The solvent effect on the polymer structure formed during the polycondensation reaction might be related with tautomerism between thioand thiol-amides, and solvents such as ethanol or water might stimulate to shift the equilibrium toward a thiolamide type, resulting in the formation of insoluble polymers.

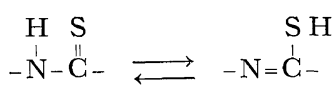

Model Reaction and Hydrolysis of O,O-Dithioesters

A model reaction between thiopropionic acidO-ethyl ester and nucleophiles such as $n$-butylamine, $n$-butyl alcohol or $n$-butyl mercaptan was carried out. Hydrolysis of DTIP and isophthalic acid diethyl ester by $2-N$ sodium hydroxide or $2-N$ hydrochloride wascar ried out in order to compare the reactivity toward nucleophiles with that toward acid or base.

Figure 9 shows the results of the reaction of thiopropionic acid-O-ethyl ester with nucleophiles, and it is seen in Figure 9 that the reaction with amine takes place at a much higher rate than that with alcohol or mercaptan. This result suggests that the rate of the polycondensation of O,O-dithioester with diols or dimercaptans might be much slower than that with diamines, although

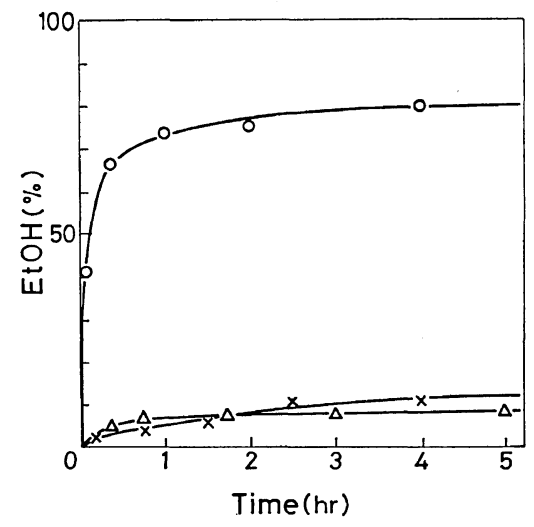

Figure 9. Rates of the condensation of $\mathrm{S}$

$\mathrm{CH}_{3} \mathrm{CH}_{2} \mathrm{COC}_{2} \mathrm{H}_{5}$ and $n$ - $\mathrm{BuNH}_{2}(\bigcirc), n$-BuOH $(\triangle)$ or $n$-BuSH $(X)$ in DMF at $30^{\circ} \mathrm{C}$ : monomer concn, $0.50 \mathrm{~mol} / l$; catalyst, $\mathrm{CH}_{3} \mathrm{ONa}, 5 \mathrm{~mol} \%$.

no experimental results are available at present.

Figure 10 represents the results of the hydrolysis of isophthalic acid-O,O-diethyl ester in comparison with ethyl isophthalate. The hydrolysis rate by base was much faster than that by acid, and the difference in the hydrolysis rate between O-thioester and ester was not significantly observed. However, the reactivity of O-thioester with nucleophiles such as amines is much higher 


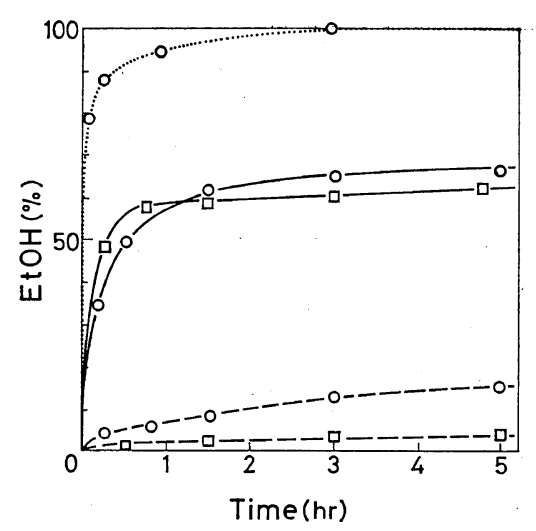

Figure 10. Rates of hydrolysis of EtOC (○) and EtOC$0.25 \mathrm{~mol} / l$; temp, $20^{\circ} \mathrm{C}$; (-), base, $2-N \mathrm{NaOH}$; $(---)$, acid, $2-N \mathrm{HCl} ;(\cdots)$, base, $2-N \mathrm{NaOH}$ at $100^{\circ} \mathrm{C}$.

than that of ordinary ester which does not react with amine at such low temperatures as described in this report. The reason why $\mathrm{O}$-thioester easily reacts with amine in spite of the fact that the hydrolysis rate of O-thioester is not much different with that of ester, is not clear yet. It is presumed that a complex formation between thiocarbonyl group and amine might take place at the transition stage of the reaction, followed by easy elimination of alcohol to form the thioamide group, since metal acetylacetonate accelerated the polycondensation reaction of $\mathrm{O}, \mathrm{O}$ dithioester with diamine, although no concrete experimental evidence for the complex formation is available.

Hydroxyl anion $\mathrm{OH}^{-}$might directly attack the thiocarbonyl carbon as in the case of the hydrolysis of ordinary ester, so the hydrolysis rate of O-thioester is not different from that of ester. Detailed studies on this problem are required for elucidation.

\section{REFERENCES}

1. R. W. Stackman and H. W. Steinmann, $A C S$ Polym. Preprints, 9, 628 (1968).

2. K. Kuze, Kogyo Kagaku Zasshi (J. Chem. Soc. Japan, Chem. Ind. Sect.), 72, 1603 (1969).

3. K. Sanui, T. Asahara, and N. Ogata, J. Polym. Sci., Part A-1, 6, 1195 (1968).

4. K. Sanui and N. Ogata, J. Polym. Sci., Part A-1, 7, 889 (1969).

5. N. Ogata and K. Sanui, J. Polym. Sci., Part A-1, 7, 2849 (1969).

6. M. Matsui, Memoirs of the College of Engineering University of Kyoto, 1, 285 (1908).

7. K. Sanui, Y. Kishimoto, and N. Ogata, Polymer J., 2, 422 (1971). 